\title{
Humanização da saúde em um serviço de emergência de um hospital público: comparação sobre representações sociais dos profissionais antes e após a capacitação
}

\author{
Humanization health at emergency service in a public hospital: \\ comparison on social representation of professional \\ before and after training
}

M aria Angélica Carvalho Andrade ${ }^{1}$

Elizabeth Artmann ${ }^{2}$

Zeidi Araujo Trindade ${ }^{3}$

${ }^{1}$ Hospital Dr. Dório Silva. Eudes Scherer de Souza s/n, Laranjeiras. 29165-680 Serra ES.

geliandrade@hotmail.com

${ }^{2}$ Departamento de

Administração e

Planejamento em Saúde,

Escola Nacional deSaúde

Pública Sérgio Arouca,

Fundação O swaldo Cruz.

${ }^{3}$ Centro de Ciências

Humanase $\mathrm{N}$ aturais,

UniversidadeFederal do

Espírito Santo.
Abstract Thisarticlepresents theresults of a study of the type before and after training in Shelter with Risk classification compared to the humanization of social representations of health among 111 health professionals in an emergency hospital. Data collection was performed using the technique of free evocation and analysis was done using the EVOC software. The results showed changes in the symbolic meaning attributed to terms inducers towards incorporation of the right perspective in the representation of the $U$ nified $\mathrm{H}$ ealth System, thetranslation of $\mathrm{H}$ umanization in health as Shelter, and the progression of understanding the Shelter, the humanistic focus to the qualification of processes of care of the users demand at emergencies. The results indicate that the differences found in the core before and after training were due to an apprenticeship, which based in peripheral elements, was able to question the core elements and interchange between the central and peripheral system, recognizingthefunctional complementarity between these two systems and the relationships between representations and practices. However, the method does not assert the persistence of such changes in the social representations of the objects studied in depth or measurethe changes in daily practices.

Key words Humanization of assistance, Public health, $\mathrm{H}$ ealth policies, Social representation
Resumo Esteartigo apresenta os resultados deum estudo do tipo antes e depois da capacitação em acolhimento com classificação de risco, que comparou as representações sociais de humanização da saúde entre 111 profissionais de saúde em uma unidade hospitalar de urgência e emergência. A coleta de dadosfoi realizada por meio da técnica de evocações livres ea análise pelo softwareEVOC. Os resultados mostraram modificação no significado simbólico atribuído aos termos indutores na direção da incorporação da perspectiva do direito na representação do Sistema Ú nico de Saúde, na tradução da humanização na saúdecomo acol himento e progressão da compreensão do acolhimento, do foco humanístico para a qualificação dos processos de atendimento da demanda dos usuários nas urgências e emergências. Os resultados indicam que as diferenças encontradas no núcleo central antese apósa capacitação foram decorrentes de uma aprendizagem que, ancorada em elementos periféricos, foi capaz de questionar o núcleo central e intercambiar elementos entre o sistema central e periférico, constatando a complementaridade funcional entre estes dois sistemas e as relações entre representações e práticas. Contudo, o método utilizado não permite afirmar a persistência de tais mudanças nas representações sociais dos objetos estudados, nem medir em profundidadeas mudanças nas práticas cotidianas.

Palavras-chave H umanização da assistência, Saúdepública, Políticasdesaúde, Representação social 


\section{Introdução}

A concretização da universalidade, da integralidade e da equidade da atenção em saúde, no cotidiano das instituições de saúde, depara-se com inúmeros problemas que persistem sem solução, impondo a urgência, seja de aperfeiçoamento do sistema, seja de mudança de rumos ${ }^{1}$.

Uma série de tecnologias de planejamento e gestão tem sido utilizada para melhorar a qualidade da assistência prestada aos usuários; porém, a maioria dos modelos adotados, principalmente pelos hospitais públicos, pouco têm contribuído para enfrentar estas questões ${ }^{2}$. As dificuldades para a implementação de um modelo de gestão alternativo decorrem principalmenteda resistência das corporações, em especial os médicos eos enfermeiros, às mudanças propostas e, também, à profissionalização da gerência. Estas práticas de resistência e/ou oposição às novas propostas de funcionamento institucional variam com a categoria profissional: a resistência passiva dos médicos traduz-se por ignorar as novas propostas, enquanto a enfermagem apresenta reações ativas à quebra do esquema anterior de funcionamento, em um processo de discussões fechadas na categoria².

Assim, para enfrentar os desafios de tornar os princípios do Sistema Ú nico de Saúde (SUS) operativos na prática, o M inistério da Saúde elaborou a Política Nacional de Humanização (PNH), na qual a humanização éentendida como um instrumento para a mudança nos modelos de atenção e gestão, tendo como foco as necessidades dos cidadãos, a produção de saúde e 0 próprio processo de trabalho em saúde, valorizando os trabalhadores e as relações sociais no trabalho ${ }^{1}$.

A proposta dehumanização da atenção à saúde surge no cenário das políticas públicas como uma oportunidade de propor, discutir e empreender um processo de mudança na cultura de atendimento vigente em toda a rede do SU ${ }^{3}$, quebrando as fronteiras impostas historicamente ${ }^{4}$. A possibilidade de mudar a cultura em longo prazo reside na capacidade de construção legitimada de novas representações que os atores podem ter em função de sua participação em processos comunicativos de apren dizagem ${ }^{5}$.

As práticas e os comportamentos dos indivíduos são orientados pela forma que os indivíduos interpretam sua realidade, enten dida como representação social. Uma representação é constituída deum conjunto de informações, decrenças, de opiniões e de atitudes a propósito de um dado objeto social ${ }^{6}$. Toda realidadeérepresentada, quer dizer, reapropriada pelo indivíduo ou pelo grupo, reconstruída no seu sistema cognitivo, integrada no seu sistema de valores, dependente de sua história e do contexto social e ideológico que o cer$\mathrm{Ca}^{6}$, funcionando como um sistema queguia para ação, orientando as reações e as relações sociais. As representações e as práticas modificam-see se transformam reciprocamente ${ }^{7}$, embora não se trate de uma influência equivalente.

Para o presente estudo, utilizou-se como aporte teórico a teoria das representações sociais (TRS), inaugurada por Serge M oscovici em 1961, e o emprego complementar da teoria do núcleo central, proposta por Abric 6 . Segundo esta teoria, as representações são estruturadas pelos sistemas central eperiférico. Baseado nesta concepção, o sistema central é constituído pelo núcleo central da representação, com funções de gerar o significado básico da representação e determinar a organização global de todos os elementos ${ }^{8}$. 0 núcleo central é marcado pela memória coletiva; reflete as condições sócio-históricas e os valores do grupo; constitui a base comum, consensual e coletivamente partilhada das representações; é estável, coerente eresistente à mudança; é relativamente pouco sensível ao contexto social e material imediato no qual a representação se manifesta. 0 sistema periférico é constituído pelos demais elementos da representação e suas funções consistem, em termos atuais e cotidianos, na adaptação à real idade concreta ena diferenciação do conteúdo da representação e, em termos históricos, na proteção do sistema central| ${ }^{8}$. Permite, ainda, a integração das experiências históricas individuais, suporta a heterogeneidade do grupo eas contradições, éevolutivo e sensível ao contexto imediato ${ }^{8}$. Não se trata de um componente menor da representação; ao contrário, ele é fundamental, posto que, associado ao sistema central, permite a ancoragem na realidade ${ }^{6}$.

0 dispositivo acolhimento com classificação de risco (ACCR), para a PNH, representa um importante disparador dos processos de mudança. Acolhimento éuma ação tecnoassistencial, que pressupõe a mudança da relação profissional/ usuário e sua rede social por meio de parâmetros técnicos, éticos, humanitários e de solidarie dade ${ }^{9}$, e classificação de risco é um processo dinâmico de identificação dos pacientes quenecessitam de tratamento imediato, de acordo com o potencial de risco, agravos à saúde ou grau de sofrimento ${ }^{9}$. Estas duas tecnologias complementares, o acolhimento com classificação de risco, tem por objetivo acolher todo usuário que pro- 
curar a instituição, fazendo uma escuta qualificada, responsável e resolutiva, pressupondo [...] a determinação deagilidadeno atendimento a partir da análise, sob a óptica de protocolo preestabelecido, do grau de necessidade do usuário, proporcionando atenção centrada no nível de complexidade enão na ordem da chegada. D esta maneira exercese uma análise (avaliação) e uma ordenação (classificação) da necessidade, distanciando-se do conceito tradicional de triagem e suas práticas de exclusão, já que todos serão atendidos 9 .

Contudo, para empreender um processo de mudança nas práticas, a PNH e seus dispositivos, como objetos representacionais, devem ser integrados cognitivamente pelos indivíduos ou grupos no seu sistema de valores. $E$, quanto à mudança, deacordo com a teoria do núcleo central, duas representações ou dois estados sucessivos de uma mesma representação devem ser considerados distintos [...] se, e apenas se, seus respectivos núcleos centrais tiverem composições nitidamente diferentes. Caso contrário, ou seja, se as diferenças se apresentam apenas no nível dos seus sistemas periféricos, trata-se de uma mesma representação que se manifesta diferentemente em função de condições circunstanciais diversas, de ordem grupal ou interindividual ${ }^{8}$.

O objetivo desta investigação foi analisar 0 papel da experiência concreta de humanização em um hospital público, por meio de implantação do acolhimento com classificação de risco, e comparar as representações sociais de SUS, humanização na saúde e acolhimento em profissionais de saúde, antes e depois da capacitação em ACCR, adotando a teoria de representações sociais em sua abordagem estrutural, visando explorar o potencial desteinstrumento como agente de mudanças.

\section{M étodo}

O estudo consistiu em avaliar uma intervenção em uma unidade deurgência e emergência em um hospital público estadual, no Espírito Santo, inserido desde 2001 no Programa Nacional de Humanização Hospitalar (PNHAH) e, posteriormente, em 2003, na Política Nacional deHumanização. Realizou-se um estudo comparativo do tipo antes e depois para medir o efeito da capacitação dos profissionais de saúde deum serviço de emergência na compreensão de humanização da saúde, com foco no dispositivo acolhimento com classificação de risco. A capacitação consistiu em um primeiro módulo com objetivo deintroduzir o acolhimento com classificação de risco no contexto do Sistema Ú nico de Saúde como um dispositivo de intervenção para a mudança nas práticas de saúde, realizado em quatro horas. Para atingir esse objetivo, utilizou-se a exposição dialogada para transmitir os conteúdos relacionados ao SUS (breve histórico de sua construção, objetivos, princípios e contextualização da instituição hospitalar na rede SUS por meio do plano diretor de regional ização do estado) eà PNH (conceito, identificação de práticas produtoras de de sumanização edehumanização, brevehistórico e inserção da instituição na PNH, objetivos, princípios, método, dispositivos, dando ênfase ao dispositivo acolhimento com classificação de risco e sua relação com a concretização do SUS).

A amostra foi selecionada a partir de convocação gerencial dos 272 profissionais de saúde da UnidadedeTrabalho deUrgência eEmergência para participar do módulo de alinhamento conceitual da capacitação em acolhimento com classificação derisco. Desses 272 profissionais convocados, apenas 121 concordaram em participar da capacitação, divididos em seis turmas, de acordo com a disponibilidade. Todos os 121 profissionais participantes foram incluídos na pesquisa, embora dez tenham sido excluídos posteriormente.

Esta pesquisa está inserida no projeto humanização nos serviços de saúde: como interferir nos processos de gestão no trabalho e produção de saúde considerando a dimensão cultural em diferentes abordagens, e foi aprovada pelo Comitêde Ética da Escola N acional de Saúde Pública Sérgio Arouca (ENSP). Após autorização do termo de consentimento livre e esclarecido para participação na pesquisa, segundo Resolução CNS n 196/96, pela direção geral e gerente da unidade deurgência e emergência, garantindo-se o anonimato dos profissionais da instituição, iniciou-se a coleta de dados.

A coleta de dados foi realizada no primeiro semestre de 2007, em dois momentos: antes de iniciar e imediatamente após a conclusão da capacitação, por duas facilitadoras, profissionais de saúde do setor de humanização da própria instituição, responsáveis pelas capacitações.

Os dados foram obtidos diretamente dos profissionais de saúde por meio da técnica das evocações ou associações livres. No campo de estudo das representações sociais, esta técnica tem por objetivo apreender a percepção da realidade de um grupo social a partir de uma composição semântica preexistente e consiste em solicitar ao indivíduo que produza todas as palavras ou expressões que possa imaginar a partir de um ou 
mais termos indutores. 0 teste consistiu em pedir aos sujeitos individualmentequeassociassem, livre e rapidamente, a partir da audição de três termosindutores: SistemaÚ nico de Saúde(SUS), humanização da saúde e acolhimento, outras palavras ou expressões, nos dois momentos referidos. Este instrumento foi autopreenchido, após a realização de um breve treinamento com outros termos indutores, diferentes daqueles a serem pesquisados. No momento de tratamento dos dados, deu-se a exclusão de dez profissionais que não responderam.

Para efeito de controle, foi utilizado o autopareamento: os dados brutos obtidos dos profissionais de saúde foram comparados com os dados obtidos desses mesmos profissionais antes e após a capacitação.

Para a análise estatística das evocações, foi utilizado o software EVOC (Ensemble de Programmes Permettant L'Analyse dês Évocations), versão 2003, que realiza cálculos estatísticos e a construção de matrizes de co-ocorrências que servem de base para a construção do "quadro de quatro casas" (ou distribuição em quatro quadrantes), por meio do qual se discriminam o núcleo central, os elementos intermediários e os elementos periféricos da representação. Na perspectiva teórica de Abric ${ }^{6}$, esta técnica de análise permite, a partir da frequência média de ocorrência das palavras evocadas e da média das ordens deevocações produzidas, a identificação dos elementos considerados centrais e periféricos na representação. As palavras que provavelmente formam o núcleo central dos termos estudados são aquelas quetiveram as maiores frequências e que foram mais prontamente evocadas, situando-se no quadrante superior esquerdo da figura, segundo a teoria utilizada ${ }^{6}$. As palavras situadas nos quadrantes superior direito einferior esquerdo são consideradas elementos intermediários, enquanto as localizadas no quadrante inferior direito são os elementos mais periféricos ${ }^{8}$.

\section{Resultados}

Os resultados são apresentados dando-se ênfase aos elementos do núcleo central, poiséa identificação do núcleo central quepermiteo estudo comparativo das representações ${ }^{6}$. Porém, inicialmente, após caracterização da amostra, serão consideradas todas as pal avras evocadas identificadas como os elementos centrais e periféricos da representação, antes e após a capacitação, não apenas para conceber igual ênfase aos elementos centrais epe- riféricos, mas também para destacar a complementaridadefuncional entreestes doissistemase, principalmente, para possibilitar a comparação entre duas representações ou dois estados sucessivos de uma mesma representação, em termos da articulação entre os dois sistemas internos e as relações entre representações e práticas ${ }^{8}$.

Dos 272 dos profissionais de saúde da Unidade de Trabalho de Urgência e Emergência do Hospital Dr. Dório Silva (HDS), 111 profissionais participaram do estudo (40,8\%). As categorias profissionais quetiveram, proporcionalmente, as maiores participações na capacitação foram: enfermeiros $(92,8 \%)$, auxiliar de enfermagem $(86,1 \%)$, técnico de enfermagem $(82,2 \%)$ e secretários de clínica ( $80 \%$ ). A penas um médico clínico $(4,1 \%)$, do total de 24 , compareceu à capacitação.

As palavras relacionadas aos indutores SUS, humanização eacolhimento, com maior frequência de evocação, antes e após a capacitação, encontram-se descritas nas Tabelas 1, 2 e 3 respectivamente.

A análise dos dados com relação ao termo indutor SUS evidenciou, no início da capacitação, que os profissionais associavam o SUS tanto com a sua prática cotidiana (hospital, lotado, dificuldade, trabalho, medicação, atendimento, cuidado eassistência médica) quanto com o processo saúde/doença, e, ainda, com entendimento do SUS como direito de todos (direito e universalidade), associado à humanização eacolhimento. A pós a capacitação, os dados demonstraram uma ampliação da compreensão dos princípios do SUS (equidade eintegralidade), sendo identificado um contexto de mudança com ênfase positiva (solução, qualidade, respeito, atendimento bom, melhoria, organização, pode melhorar, qualificação, agilidade, esperança, mudança, prioridade) einclusão da responsabilização (responsabilidade) como fatores importantes para a identificação do SUS.

O s elementos constituintes do núcleo central da representação social do SUS, compartilhados antes e após a capacitação, parecem revelar um entendimento da finalidade do SUS para a saúde da população (saúde, universalidade, atendimento). A palavra humanização, no núcleo central do SUS, pode referir a uma dimensão de sua necessidade para 0 atendimento de saúde à população. As diferenças destacadas entre os elementos constituintes do núcleo central da representação social do SUS dizem respeito às palavras doença ehospital, encontradas no núcleo central apenas antes da capacitação eque, após a capaci- 


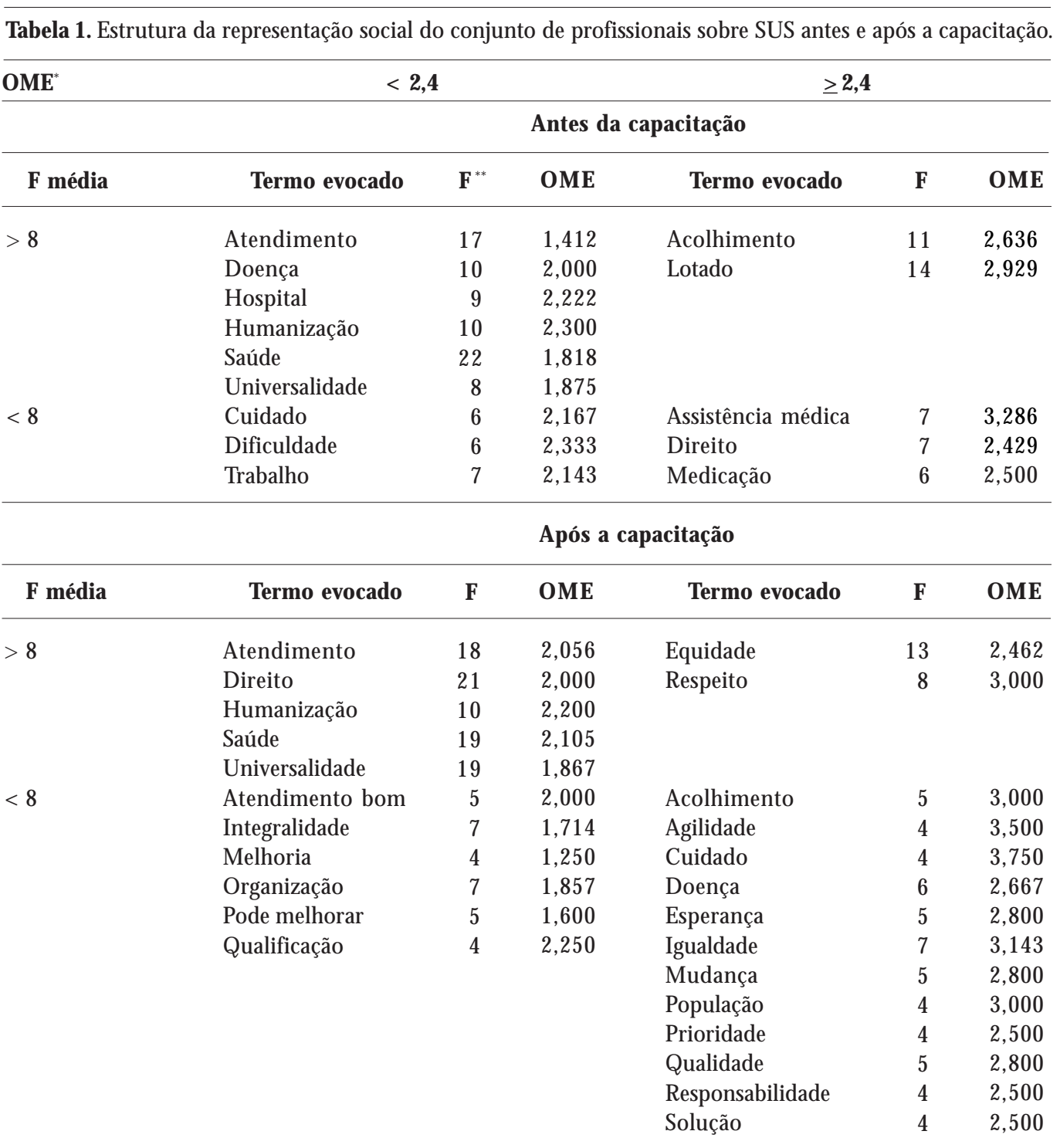

${ }^{*} \mathrm{OME}=$ Ordem média das evocações; ${ }^{* *} \mathrm{~F}=$ Frequência.

tação, "migram" para o sistema periférico e para fora da estrutura da representação, respectivamente. Além disso, após a capacitação, reafirmam-se os elementos centrais do termo SUS, associando-sea noção de cidadania, expressa pelo "trânsito" da palavra direito do sistema periférico para o núcleo central.

Com relação à temática humanização na saúde, antes da capacitação, os dados apresentados mostraram que a estrutura da representação social do objeto humanização encontra-se associada a uma concepção humanística (amor, cuidado, respeito, dignidade, atenção, carinho, ser humano, igualdade), relacionada a um comportamento voltado para a qualificação do atendi- mento (acolhimento, atendimento bom, melhoria, organização). Após a capacitação, o termo humanização na saúde, além das concepções anteriores, ganhou importância (necessário) e concretude, sendo associado à ação (atendimento, empatia, ouvir) e relacionado a resultados positivos (qualidade, resolutividade).

As palavras em destaque no núcleo central do termo humanização na saúde indicam que antes da capacitação estão, igualmente, relacionadas ao acolhimento ea uma concepção humanística (amor, cuidado e respeito) ligada a uma qualificação do atendimento da demanda (atendimento bom e melhoria). Após a capacitação, observa-se o deslocamento dos elementos, asso- 


\begin{tabular}{|c|c|c|c|c|c|c|c|}
\hline \multirow[t]{28}{*}{ 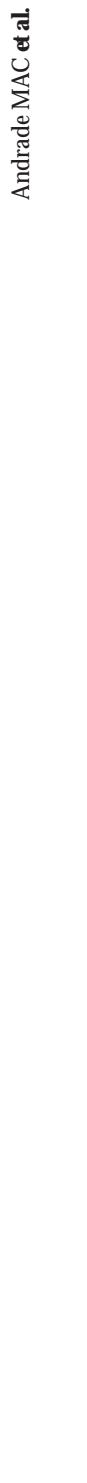 } & $\begin{array}{l}\text { Tabela 2. Es } \\
\text { e após a cap }\end{array}$ & la representação social & conj & o de pro & onais sobre Humaniz & ão na & de antes \\
\hline & \multirow[t]{2}{*}{$\mathrm{OME}^{*}$} & \multicolumn{4}{|c|}{$<2,3$} & \multicolumn{2}{|l|}{$\geq 2,3$} \\
\hline & & \multicolumn{6}{|c|}{ Antes da capacitação } \\
\hline & F média & Termo evocado & $\mathrm{F}^{* *}$ & OME & Termo evocado & $\mathrm{F}$ & OME \\
\hline & \multirow[t]{6}{*}{$>10$} & Acolhimento & 16 & 1,563 & & & \\
\hline & & Amor & 19 & 2,211 & & & \\
\hline & & Atendimento bom & 13 & 1,692 & & & \\
\hline & & Cuidado & 10 & 2,000 & & & \\
\hline & & Melhoria & 11 & 1,727 & & & \\
\hline & & Respeito & 22 & 2,273 & & & \\
\hline & \multirow[t]{6}{*}{$<10$} & \multirow[t]{5}{*}{ Dignidade } & \multirow[t]{5}{*}{7} & \multirow[t]{5}{*}{2,286} & Atenção & 8 & 2,750 \\
\hline & & & & & Carinho & 8 & 2,625 \\
\hline & & & & & Igualdade & 7 & 2,571 \\
\hline & & & & & Organização & 6 & 2,500 \\
\hline & & & & & Ser humano & 8 & 2,375 \\
\hline & & \multicolumn{6}{|c|}{ Após a capacitação } \\
\hline & F média & Termo evocado & $\mathrm{F}$ & OME & Termo evocado & $\mathrm{F}$ & OME \\
\hline & \multirow[t]{5}{*}{$>12$} & \multirow[t]{3}{*}{ Acolhimento } & \multirow[t]{3}{*}{16} & \multirow[t]{3}{*}{1,750} & Amor & 15 & 2,600 \\
\hline & & & & & Entender & 12 & 2,583 \\
\hline & & & & & Respeito & 26 & 2,385 \\
\hline & & Atendimento & 9 & 2,111 & Carinho & 9 & 2,556 \\
\hline & & Atendimento bom & 8 & 1,250 & Cuidado & 7 & 3,000 \\
\hline & \multirow[t]{6}{*}{$<12$} & Atenção & 9 & 1,667 & Dignidade & 5 & 3,600 \\
\hline & & Empatia & 6 & 1,500 & Igualdade & 6 & 2,500 \\
\hline & & Melhoria & 5 & 1,800 & Ouvir & 9 & 2,333 \\
\hline & & Necessário & 5 & 2,200 & Qualidade & 9 & 2,333 \\
\hline & & Organização & 6 & 2,167 & Resolutividade & 5 & 2,400 \\
\hline & & Ser humano & 8 & 1,375 & Solidariedade & 5 & 3,400 \\
\hline
\end{tabular}

* OME = Ordem média das evocações; ${ }^{* *} \mathrm{~F}=$ Frequência.

ciados à concepção humanística e à qualificação do atendimento, do núcleo central para o periférico, e o termo humanização na saúde passa a ser representado apenas pela palavra acolhimento. Os elementos periféricos, associados ao sistema central, permitem a ancoragem na realida$\mathrm{de}^{6}$. Assim, as dimensões de importância e concretude que aparecem entre os el ementos periféricos, após a capacitação, sinalizam que a representação social de humanização na saúde como acolhimento expressa a importância desta ferramenta para lidar com a problemática da qualidade do acesso e da recepção dos usuários nos serviços de saúde.

Quando a palavra acolhimento se torna o alvo da associação dos participantes, antes da capacitação, evidenciou-se que a temática é vin- culada às questões relacionais afetivas, também em uma concepção humanística (ajuda, amor, carinho, receptividade, atenção e respeito), porém associada a condições necessárias para a qual ificação da prática (acolhimento, atendimento, cuidado, entender, humanização, ouvir eatendimento bom). Entretanto, os dados mostraram que, após a capacitação, esta associação foi acrescida da dimensão de organização de processos de trabalho (organização, prioridade, direcionamento, encaminhamento) e perfil profissional (paciência e solidariedade), ligada a um contexto positivo (satisfação e melhoria).

A análise comparativa do núcleo central da representação social dos profissionais, anteseapós a capacitação, revela uma associação diferencial de acolhimento, expressa pela "saída", do núcleo 
Tabela 3. Estrutura da representação social do conjunto de profissionais sobre acolhimento antes e após a capacitação.

\begin{tabular}{|c|c|c|c|c|c|c|}
\hline \multirow[t]{2}{*}{$\mathrm{OME}^{*}$} & \multicolumn{3}{|c|}{$<2,4$} & \multicolumn{3}{|c|}{$\geq 2,4$} \\
\hline & \multicolumn{6}{|c|}{ Antes da capacitação } \\
\hline $\mathrm{F}$ média & Termo evocado & $\mathrm{F}^{* *}$ & OME & Termo evocado & $\mathrm{F}$ & OME \\
\hline \multirow[t]{4}{*}{$>15$} & Ajuda & 15 & 2,000 & Respeito & 22 & 2,909 \\
\hline & Amor & 19 & 2,263 & & & \\
\hline & Carinho & 15 & 2,000 & & & \\
\hline & Receptividade & 16 & 1,438 & & & \\
\hline \multirow[t]{9}{*}{$<15$} & Abraçar & 7 & 2,143 & Atendimento bom & 8 & 2,750 \\
\hline & Acolhimento & 11 & 1,818 & & & \\
\hline & Atendimento & 9 & 1,778 & & & \\
\hline & Atenção & 8 & 2,250 & & & \\
\hline & Cuidado & 9 & 1,889 & & & \\
\hline & Entender & 10 & 2,300 & & & \\
\hline & H umanização & 11 & 2,182 & & & \\
\hline & Ouvir & 13 & 2,154 & & & \\
\hline & \multicolumn{6}{|c|}{ Após a capacitação } \\
\hline F média & Termo evocado & $\mathrm{F}$ & OME & Termo evocado & $\mathrm{F}$ & OME \\
\hline \multirow[t]{6}{*}{$>8$} & Amor & 16 & 1,875 & Ajuda & 11 & 2,543 \\
\hline & Atendimento & 10 & 1,600 & Encaminhamento & 9 & 3,333 \\
\hline & Atenção & 13 & 2,231 & Entender & 8 & 2,500 \\
\hline & Cuidado & 13 & 2,308 & H umanização & 14 & 2,500 \\
\hline & Ouvir & 22 & 2,318 & Respeito & 27 & 2,481 \\
\hline & Receptividade & 13 & 1,385 & & & \\
\hline \multirow[t]{5}{*}{$<8$} & Acolhimento & 4 & 1,250 & Carinho & 7 & 2,571 \\
\hline & Atendimento bom & 7 & 1,571 & Direcionamento & 4 & 2,750 \\
\hline & Organização & 5 & 1,400 & M elhoria & 4 & 2,500 \\
\hline & Prioridade & 4 & 2,000 & Paciência & 7 & 2,429 \\
\hline & Satisfação & 4 & 2,250 & Solidariedade & 6 & 2,833 \\
\hline
\end{tabular}

* OME = Ordem média das evocações; ${ }^{* *} \mathrm{~F}=$ Frequência.

central para o periférico, de algumas palavras ligadas a uma concepção mais humanística (ajuda, carinho) e pela inserção no núcleo central de novos elementos "vindos" do sistema periférico (atendimento, atenção, cuidado e ouvir). Estes dados sugerem que, com a capacitação, os profissionais atribuem um sentido quetraduzem uma progressão do foco humanístico para a qualificação dos processos de atendimento da demanda dosusuáriosnasurgências eemergências do SUS.

\section{Discussão}

As representações sociais são produtos da realidade cotidiana que se concretizam e se transformam a partir da ação ${ }^{10}$. Com a perspectiva aber- ta pelas representações sociais de profissionais de saúde, esta pesquisa mostrou uma modificação no significado simbólico atribuído ao SUS, humanização e acolhimento, com a capacitação. A capacitação possibilitou mudanças na direção da incorporação da perspectiva do direito à representação do SUS, na tradução da humanização na saúde como acolhimento, ou seja, como uma ferramenta para lidar com a problemática da qualidade do acesso nos serviços de saúde, ea progressão na compreensão do acolhimento, do foco humanístico para a qualificação dos processos de atendimento da demanda dos usuários nas urgências e emergências do SUS. M as, embora se possa considerar que houve uma modificação inicial na representação social do SUS, humanização e acolhimento, após a capacitação, 
não se pode afirmar a persistência e profundidade da mudança.

Entretanto, apesar das limitações, consequência do caráter exploratório deste estudo e da delimitação da análise ao estudo comparativo das representações, épossível inferir queas diferenças encontradas no núcleo central antes e após a capacitação foram decorrentes de uma aprendizagem significativa, em que o material da aprendizagem se relacionou com os conhecimentos prévios, já presentes no sistema periférico da representação, possibilitando esta modificação na representação social do SUS, humanização e acolhimento.

A aprendizagem é considerada significativa quando é motivada pelo desejo ativo dos participantes pela apropriação de novos saberes e práticas $^{4}$ e ocorre quando o seu conteúdo é considerado significativo, ou seja, quando se relaciona com aquilo que a pessoa já sabe, equando há motivação pessoal para relacionar o que se aprende com o que já se sabe e para interagir com o outro de forma aberta 4 . Esta inferência respalda-sena análise da avaliação realizada com os participantes da capacitação, em que 60,2\% consideraram o conteúdo do curso ótimo e 39,8\%, bom. E, com relação à motivação pessoal para a capacitação, para $51,7 \%$ dos participantes foi ótimo e para $47,5 \%$, bom. Importante ressaltar o viés existente na população estudada, pois provavelmente, em função da não obrigatoriedade da participação na capacitação, compareceram os profissionais que já tinham interesse em humanização.

As proposições da teoria do núcleo central quanto aos estudos comparativos das representações sociais evidenciam a relação entre as práticas e as representações. $\mathrm{Na}$ avaliação dos processos envolvidos na mudança de atitudes, na abordagem estrutural das representações sociais, Abric ${ }^{6}$ demonstra que o questionamento (ataque) do núcleo central é necessário para a transformação de uma representação. Assim, uma afirmação possível é a de que a aprendizagem significativa, ancorada em elementos periféricos, é capaz de questionar o núcleo central e intercambiar elementos entre o sistema central e periférico, constatando a complementaridade funcional entre estes dois sistemas e as relações entre representações e práticas.

Os dados mais interessantes que surgem da análise neste trabalho confirmam a importância do elemento periférico no estudo dos processos de transformação das representações, sendo um indicador bastante pertinente de futuras modificações ou um sintoma indiscutível de uma evolução nas situações nas quais a transformação de uma representação está em andamento ${ }^{6}$. Porém, uma vez iniciado o processo de transformação das representações, segundo Flament, citado por Sá8, isto não quer dizer que ele deva ir obrigatoriamente até 0 efetivo surgimento de uma nova representação. Como pré requisito para a mudança representacional, este autor sustenta a existência de um esquema sequencial que consiste na modificação das circunstâncias externas; modificação das práticas sociais; modificação dos prescritores condicionais emodificação dos prescritores absolutos (núcleo central) ${ }^{8}$. E, ainda, somente se essas novas condições epráticas persistem e, principal mente, sesão percebidas como irreversíveis, o núcleo central pode chegar de fato a ter sua composição alterada e, portanto, surgir uma representação realmente diferente do objeto ${ }^{8}$.

$\mathrm{Na}$ medida em que a aprendizagem no trabalho mobiliza e convida à ação ativa, ela é considerada uma ação política ${ }^{4}$. Assim, para a construção de novas representações e práticas, destaca-se a importância do comprometimento institucional com a mudança na direção da humanização, expresso pela garantia de participação de todos os atores envolvidos; pelo desenvolvimento de ações concretas, que garantam a crença dos atores na irreversibilidade da mudança; e por um processo permanentedeaprendizagem significativa. É preciso criar condições favoráveis para propiciar a permanente reflexão sobre as práticas e a produção de coletivos e construir novos pactos de convivência e práticas que aproximem os serviços de saúde dos princípios do SUS4.

$M$ as, nas organizações em geral, segundo alguns autores ${ }^{11,12}$, existe uma cultura que inibe a aprendizagem e a comunicação, caracterizada pela concentração do poder no topo da organização, poder desequilibrado, estrutura vertical, autoritarismo; foco nos sistemas e não nas pessoas; descrédito da possibilidade de mudanças (ceticismo); falta de tempo para a aprendizagem; abordagem pouco histórica dos problemas, pre domínio de uma visão de tratamento de sintomas; comunicação transmissional vertical, falta de uma comunicação aberta, lateral; predomínio do individualismo, descrédito do trabalho em equipe e padrão de liderança-herói, carismática, que se esconde, eque não reconhece erros e vulnerabilidade. $E$, ainda, nas organizações de saúde, estas características são acrescidas do padrão apresentado pelas organizações profissionais, caracterizado por um processo de autonomia dos centros operacionais, coordenação do 
trabalho por meio do ajustamento mútuo, debilidade da tecnoestrutura e ausência de linha hierárquica nítida. Isto resulta em uma forte diferenciação com várias dimensões, tais como diferenciação entre o mundo administrativo e o mundo assistencial; diferenciação entre logística e centro operacional e diferenciação no centro operacional ${ }^{13}$. Estas características, para Rivera e Artamann ${ }^{5}$, dificultam a possibilidade de um projeto gerencial que enfatize a integração intrainstitucional, a racionalidadeeconômica da missão específica e a negociação de uma rede de cuidados com os outros estabelecimentos da ambiência imediata. Dificultam, mas não impossibilitam a transformação e reorganização das representações e práticas.

Segundo Artmann e Rivera ${ }^{11}$, estabelecer 0 modo como a gestão pode apoiar 0 atendimento humanizado constitui o grande desafio. Desta forma, a questão que se coloca é a de como implementar um modelo de gestão que viabilize a construção destas novas condições externas e práticas sociais, pré requisitos para a mudança representacional, superando, principalmente, as dificuldades decorrentes: da resistência dos profissionais às mudanças propostas; da profissionalização gerencial necessária à concretização de ações e da frequente descontinuidade gestora. A característica gerencial organizativa que responde a esta questão é representada pela necessi dade de construir um sistema de gestão coerente com processos comunicativos de aprendizagem afinados com a proposta de humanização ${ }^{11}$.
A abordagem das representações sociais, tanto no plano teórico como no empírico, conduz, necessariamente, à cultura ${ }^{14}$. Referindo-se ao conceito de cultura como recurso, Artmann e Rivera ${ }^{11}$ propõem um sistema de gestão comunicativa para operar indiretamente como reforço dos traços da nova cultura que emerge e que traz alguns elementos de uma cultura de humanização e comunicação. Para estes autores ${ }^{11}$, estas dificuldades apontadas poderiam ser superadas com a utilização de ferramentas de gestão estratégica, desenhadas para organizações profissionais, com base no respeito ao dado cultural da autonomia profissional dos centros operadores, que valorizam as estratégias de negociação e cooperação.

A pesar da teoria e da pesquisa do núcleo central fundamentarem-se, desde suas origens, em uma perspectiva metodológica experimental, não basta buscar inferir as representações a partir de seus suportes discursivos manifestos ${ }^{8}$. A mudança (das práticas e/ou representações) se refere à história enão à ação de variáveis descontextualizadas e monológicas ${ }^{7}$. Assim, é preciso articular esses dados com aqueles provenientes da investigação das práticas vigentes no grupo sob estudo, porque estas são as principais fontes das cognições condicionais, quese manifestam mais prontamente no discurso espontâneo ${ }^{8}$, que, conformeFlament, citado por Sá, está longe de revelar a complexidade das representações sociais. Portanto, o método utilizado não permite afirmar a persistência detais mudanças nas representações sociais dos objetos estudados nem medir em profundidade as mudanças nas práticas cotidianas.

\section{Colaboradores}

M AC Andrade, E Artmann e ZA Trindade participaram igualmente de todas as etapas da elaboração do artigo. 


\section{Referências}

1. Brasil. Ministério da Saúde. Política Nacional de Humanização: HumanizaSUS - Documento-base. 3a ed. In: Passos E, Benevides R, organizadores. Formação de apoiadores para a política nacional de humanização da gestão e da atenção à saúde. Leituras complementares. Rio de Janeiro: Fiocruz; 2006. p. 13-32.

2. Cecílio LCO. A modernização gerencial dos hospitais públicos: o difícil exercício da mudança. Rev. Adm. Pública 1997; 31(3):36-47.

3. Brasil. M inistério da Saúde. Secretaria Executiva. Núcleo Técnico da Política Nacional de Humanização. HumanizaSU S: política nacional de humanização. Brasília (DF): M inistério da Saúde; 2004.

4. Brasil. Ministério da Saúde. Secretaria de Gestão do Trabalho e da Educação na Saúde. Departamento de Gestão da Educação na Saúde. Curso de formação de facilitadores de educação permanente em saúde: unidade de aprendizagem práticas educativas no cotidiano do trabalho em saúde. Rio de Janeiro: Ministério da Saúde/Fiocruz; 2005.

5. Rivera FJU, Artmann E. Planejamento e gestão em saúde: flexibilidade metodológica e agir comunicativo. In: Rivera FJU. Análise estratégica em saúde e gestão pela escuta. Rio de Janeiro: Fiocruz; 2003. p. $17-35$.

6. Abric JC. A abordagem estrutural das representações sociais. In: Moreira ASP, Oliveira DC, organizadoras. Estudos interdisciplinares de representação social. Goiânia (GO): AB Editora; 1998. p. 27-38.

7. Rouquette M. Representações e Práticas Sociais: Alguns Elementos Teóricos. In: Moreira ASP, Oliveira $D C$, organizadoras. Estudos interdisciplinares de representação social. Goiânia (GO): AB Editora; 1998. p. 39-46.

8. Sá CP. Representações sociais: teoria e pesquisa do núcleo central. Temas em Psicologia 1996; 4(3):19-33.

9. Brasil. Ministério da Saúde. Acolhimento em saúde e acolhimento com classificação de risco. In: Passos $E$, Benevides $R$, organizadores. Formação de apoiadores para a política nacional de humanização da gestão e da atenção à saúde. Atividades. Rio de Janeiro: Fiocruz; 2006. p. 85-106.
10. Oliveira DC, Sá CP, Fischer FM, Martins IS, Teixeira LR. Futuro e liberdade: 0 trabalho e a instituição escolar nas representações sociais de adolescentes. Estud. psicol.(N atal) 2001; 6(2):245-258.

11. Artmann E, Rivera FJU. Humanização no atendimento e gestão comunicativa. In: Deslandes SF, organizadora. Humanização dos cuidados em saúde: conceitos, dilemas e práticas. Rio de Janeiro: Fiocruz; 2006. p. 205-231.

12. Schein E. Guia de sobrevivência da cultura corporativa. Rio de Janeiro: José Olímpio Editora; 1999.

13. Mintzberg H. A organização profissional. In: Mintzberg H, Lampel J, Quinn JB, Ghoshal S. O processo da estratégia: conceitos, contextos e casos selecionados. 4a ed. Porto Alegre: Bookman; 2006.

14. Jodelet $D$. Presença da cultura no campo da saúde. In: Almeida AM O, Santos M FS, Diniz GRS, Trindade ZA, organizadoras. Violência, exclusão social e desenvolvimento humano. Estudos em representações sociais. Braślia (DF): Editora Universidade de Brasília; 2006. p. 75-109.

Artigo apresentado em 09/10/2008 A provado em 24/03/2009

Versão final apresentada em 26/04/2009 